\title{
Chiroptical Responses of D-/L-Penicillamine-Capped Gold Clusters under Perturbations of Temperature Change and Phase Transfer \\ Hiroshi Yao, ${ }^{*}$ Toshiyuki Fukui, and Keisaku Kimura
}

\begin{abstract}
Graduate School of Material Science, University of Hyogo, 3-2-1 Koto, Kamigori-cho, Ako-gun, Hyogo 678-1297, Japan
\end{abstract}

\section{Absorption Spectra of $1_{D}$ and $1_{L}$ in Aqueous Solution as a Function of Temperature}

Figure $\mathrm{S} 1$ shows the UV-visible absorption spectra of compound $\mathbf{1}_{\mathbf{D}}$ and $\mathbf{1}_{\mathrm{L}}$ as a function of temperature $\left(20\right.$ and $\left.40{ }^{\circ} \mathrm{C}\right)$. The spectra were recorded using a J-820 spectropolarimeter. In each compound, the absorption spectra measured at 20 and $40{ }^{\circ} \mathrm{C}$ were almost identical.
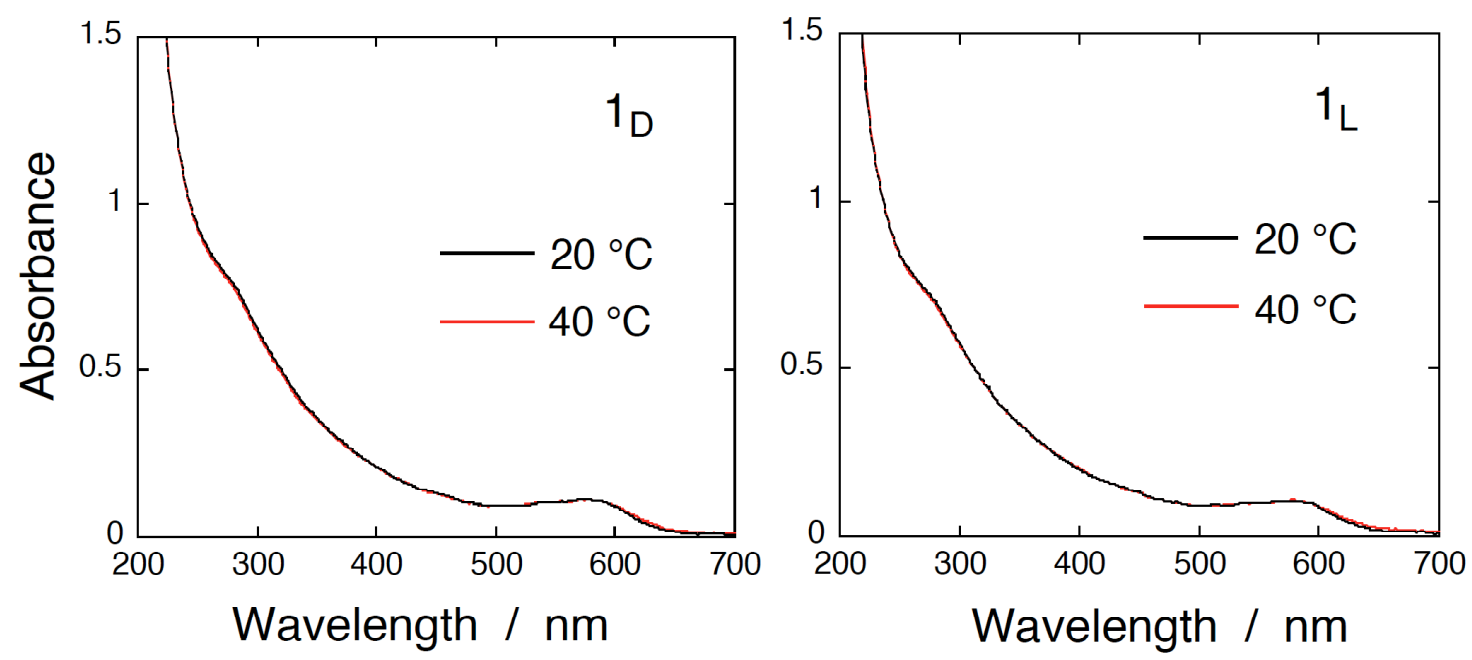

Figure S1. UV-visible absorption spectra of compounds $\mathbf{1}_{\mathrm{D}} / \mathbf{1}_{\mathrm{L}}$ as a function of temperature (20 and $\left.40{ }^{\circ} \mathrm{C}\right)$.

\section{Quantitative Analysis for the Phase Transfer of Penicillamine-Capped Gold Clusters}

In the phase transfer of penicillamine-capped gold clusters across the water/toluene interface, 1:1 ion-pair formation between the surface carboxylate anions and the tetraoctylammonium cations is expected (ref. 23 in the text). To verify this behavior, the following experiments were 
conducted.

At first, elemental analysis of the Au-D-Pen powder sample was conducted using an energy dispersive X-ray (EDX) spectroscopy. The spectrum of EDX was obtained with an EDAX DX-4 system. Figure S2-a shows a typical EDX spectrum excited by an electron beam at $9 \mathrm{kV}$. In the spectrum, the peak of $\mathrm{Na}$ comes from the sodium salt of the surface penicillamine, and that of $\mathrm{Si}$ is due to the silicon substrate used.

On the basis of the spectrum, we could determine the molar ratio of gold to the surface organics as the most reliable value to be $1.0 \sim 1.1$, suggesting that the organics of $44-46 \mathrm{wt} \%$ were contained in the powder sample.

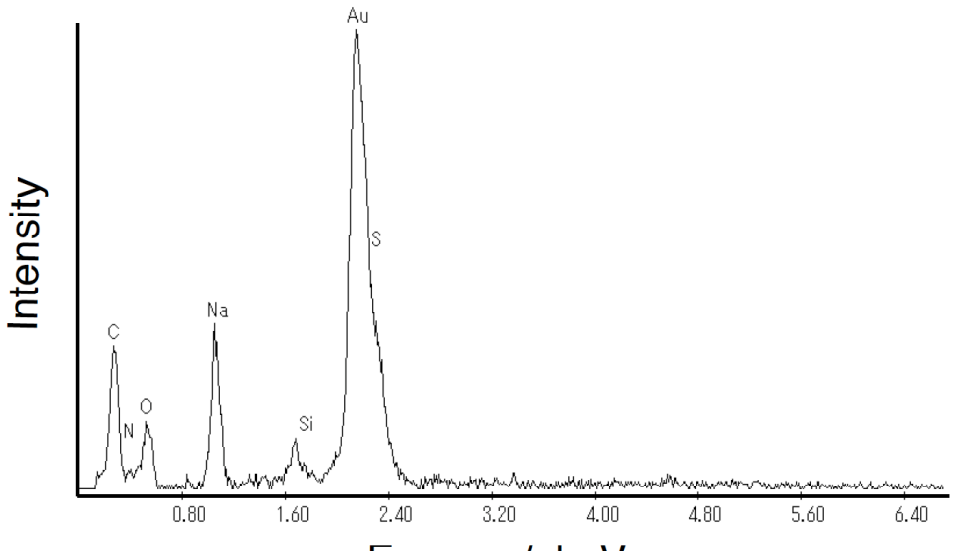

Energy / keV

Figure S2. Typical EDX spectrum of the Au-D-Pen powder sample.

Then the quantitative experiments on the phase transfer were conducted as follows: When 3 $\mathrm{mL}$ of aqueous solution containing the gold cluster powder $(0.75 \mathrm{mg})$ and $3 \mathrm{~mL}$ of toluene containing $\mathrm{TOABr}$ at a different concentration $\left(3.42-54.8 \times 10^{-7} \mathrm{~mol}\right)$ were mixed vigorously, the pale brownish cluster transferred to a toluene phase. About 10 min later, absorption spectra were measured for each sample. Figure S3-a shows the absorption spectrum of each transferred gold cluster sample at a different $\mathrm{TOABr}$ concentration normalized to that of the surface organics
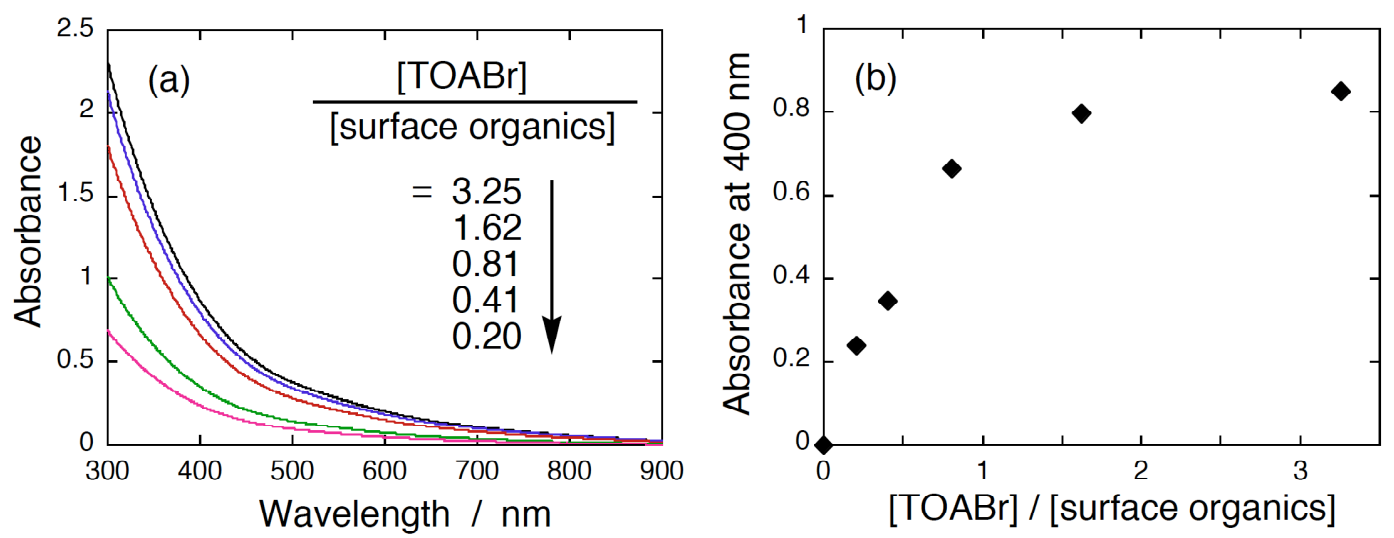

Figure S3. (a) Absorption spectra of transferred gold clusters in toluene as a function of $\mathrm{TOABr}$ concentration. (b) Relationship between the absorbance at $400 \mathrm{~nm}$ for the transferred clusters and [TOABr]/[surface organics]. 
of the cluster (or $[\mathrm{TOABr}] /[$ surface organics]) in toluene. Note that the ratio $[\mathrm{TOABr}] /[$ surface organics] was corrected with the obtained maximum transfer yield to toluene ( $85 \%)$. With an increase in the $\mathrm{TOABr}$ concentration, the absorbance firstly increased proportionally and then saturated. Figure S3-b shows the relationship between the absorbance at $400 \mathrm{~nm}$ and the normalized concentration of $\mathrm{TOABr}$ in toluene. We can see the phase-transfer saturation at around $[\mathrm{TOABr}] /[$ surface organics] $\sim 1.0$, indicating that 1:1 ion-pair formation is likely under the phase transfer. 